\title{
Comparison of Homocystiene Level in Patients with and without Androgenetic Alopecia S.H.Abd El Rahman ${ }^{1}$, J.H.Sabry ${ }^{2}$ and Z.A.Abd Elhamid \\ ${ }^{1}$ Dermatology \& Andrology Dept., Faculty of Medicine, Benha Univ, Benha, Egypt \\ ${ }^{2}$ Clinical and Chemical Pathology Dept, Faculty of Medicine, Benha Univ., Benha, Egypt \\ E-Mail: zahraa-40@yahoo.com
}

\begin{abstract}
Androgenetic alopecia (AGA), is the most common form of hair loss both in men and women, it is caused by transformation of the terminal hair in to vellus hair. Homocysteine is a sulfhydryl containing non-protein coding amino acid formed mainly as a byproduct in the methionine metabolism. Compare homocysteine level in patients with and without androgenetic alopecia and evaluate the relation between homocysteine and BMI and smoking in both studied groups. 60 patients with androgenetic alopecia and 20 age and sex matched healthy volunteers subjected to age, sex, body mass index (BMI), smoking history, laboratory investigation for measurement of the serum level of homocystiene. serum homocystiene level was found to be increased in androgenetic alopecia patients combared to controls. Homocystiene showed a significant $(\mathrm{p}<0.05)$ positive correlation with BMI and smoking. This prospective study showed that there were association between elevated homocystiene level ,smoking,BMI, and severity of androgenetic alopecia in addition to serum level of homocystiene can be used as an early prediction for AGA diagnosis.
\end{abstract}

Keyword: Androgenetic alopecia, Homocystiene, Body mass index.

\section{Introduction}

Androgenesis alopecia (AGA), is those A large portion regular manifestation about hair reduction both On men and ladies Furthermore may be described Toward An progressive reduction for hair diameter, it is brought on Toward conversion of the terminal hair in with vellus hair [1]. Those Ludwig order is the vast majority regularly utilized to surveying those seriousness of female androgenetic alopecia (FAGA), Also this recognizes three levels for seriousness [2]. Androgenesis alopecia need been discovered with make connected with coronary supply route infection (CAD) [3]. Those well-known danger figures about lowlife are family history $(\mathrm{FH})$ from claiming CAD, expanded muscle to impostor list (BMI) [4], focal obesity, Also dyslipidemia[5]. Those newer danger figures are serum lipoprotein-a (SL-a) , homocysteine (SH), Furthermore serum adiponectin (SA) [6] androgenesis alopecia need been indicated on be connected with different abnormalities, for example, such that insulin response safety (IR), hypertension [7] , abnormal serum lipid profiles [8], corpulence, prostate malignancy, generous prostatic hyperplasia Also some natural factors, for example, smoking auto [9]. Homocysteine will be a sulfhydryl holding non-protein coding amino structured basically Likewise a side effect in the methionine digestion system [10]. There need been An critical connection the middle of hyperhomocysteinemia What's more cardiovascular malady Furthermore its difficulties for example, such that heart strike Furthermore strokes. It is accepted that hyperhomocysteinemia prompts endothelial cell damage, decrease in the adaptability of vessels, and alters the methodology of haemostasis. Hyperhomocysteinemia might prompt a upgrade of the unfriendly impacts about danger figures like smoking, lipid and lipoprotein metabolism, and in addition advancement of the improvemen about aggravation [11].

\section{Subjects and methods}

This is a case control study which was include sixty patients with androgenetic alopecia and twenty age and sex matched healthy volunteers. Patients with AGA, normal hepatic and renal functions, normal thyroid and adrenal assessment and being willing to participate in the study.

\subsection{Exclusion criteria}

Any patients with any of the following condition was excluded from this study.Other disease affecting level of homocysteine in blood (Liver, renal or thyroid dysfunction or megaloblastic anemia or neuropsychiatric illness).Taking medications which may affect homocysteine level (Vitamin B complex or Vitamin C or folic acid.Any other diseases causing hair loss as telegon effluvium.

\subsection{Administrative design}

The Research Ethical Committee of Benha Faculty of Medicine was approved this study.

\subsection{Ethical consideration}

Before taking blood samples, a written informed consent was taken from each subject in both studied groups.

\subsection{Methods}

Patients was subjected to Demographic data such as age, body mass index (BMI), smoking history, Ludwig (1977) classifications was used to assess the degree of AGA.

\subsection{Laboratory investigation}

Measurement of the serum level of homocystiene , venous blood sample $(5 \mathrm{ml})$ will be taken from all studied subjects to assess serum homocystien in all subjects. Samples will be collected in sterile tubes. All methods will be performed according to the manufacturer's 
instructions. Blood will be allowed to clot, centrifuge, and separate into serum in sterile tubes and store at $-20 \mathrm{C}$ until analysis.

\subsection{Statistical analysis}

Qualitative data were summarized in the form of frequency and percentage. Mean and SD were obtained for quantitative data, while categorical data were presented by number and percentage. One way analysis of variance (ANOVA) test, paired and independent sample ttests were used for comparing means between groups.
Tests used for association were Chi square (X2) or MontCarlo Exact test (MCET). P -value was adopted to be $<0.05$.

\section{Results and discussion}

The age of patients ranged between 19-62 years with a mean of $41.3 \pm 10.4$ years, while age of the control group ranged between 22-63 years with a mean of $39.3 \pm 11.0$. There was insignificant difference between patients and control groups regarding age .(p>0.05, table 1$)$.

Table (1) Comparing between patients and controls regarding age and sex.

\begin{tabular}{|c|c|c|c|c|c|}
\hline \multirow[t]{2}{*}{ Variable } & & $\begin{array}{c}\text { Patients } \\
(\mathrm{N}=60)\end{array}$ & $\begin{array}{c}\text { Controls } \\
(\mathrm{N}=20)\end{array}$ & \multirow[t]{2}{*}{$\begin{array}{c}\text { Test of } \\
\text { significance }\end{array}$} & \multirow[t]{2}{*}{$\mathbf{P}$} \\
\hline & & No. $\%$ & No. $\%$ & & \\
\hline Age (ys) & $\begin{array}{c}\text { Mean } \pm \text { SD } \\
\text { Range }\end{array}$ & $\begin{array}{c}41.3 \pm 10.4 \\
19-62 \\
\end{array}$ & $\begin{array}{c}39.3 \pm 11.0 \\
22-63\end{array}$ & $\begin{array}{c}\text { St."t"= } \\
0.75\end{array}$ & $0.45(\mathrm{NS})$ \\
\hline
\end{tabular}

Table (2) Show that the mean level of homocystiene was significantly higher (p value <0.001) in patients group (11.7 \pm 9.5

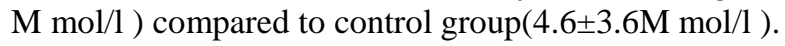

Table (2) Comparing serum homocystiene level among studied groups.

\begin{tabular}{|c|c|c|c|c|c|c|c|c|}
\hline \multirow{2}{*}{ Variable } & \multicolumn{3}{|c|}{ Patients $(\mathrm{N}=30)$} & \multicolumn{3}{|c|}{ Controls $(\mathrm{N}=\mathbf{2 0})$} & \multirow{2}{*}{$\begin{array}{c}\mathrm{Z}_{\mathrm{MWU}} \\
\text { test }\end{array}$} & \multirow[t]{2}{*}{$\mathbf{P}$} \\
\hline & $\begin{array}{l}\text { Mean } \pm \\
\text { SD }\end{array}$ & Range & $\begin{array}{c}\text { Median } \\
\text { (IQR) }\end{array}$ & $\begin{array}{c}\text { Mean } \pm \\
\text { SD }\end{array}$ & Range & $\begin{array}{c}\text { Median } \\
\text { (IQR) }\end{array}$ & & \\
\hline $\begin{array}{c}\text { homocystiene } \\
\text { (M mol/L) }\end{array}$ & $11.7 \pm 9.5$ & $3.1-37.4$ & $\begin{array}{l}7.5 \\
(5.2-13)\end{array}$ & $4.6 \pm 3.6$ & $1.5-14.6$ & $\begin{array}{l}3.2 \\
(2.5-4.9)\end{array}$ & 4.63 & $\begin{array}{l}<0.001 \\
\text { (HS) }\end{array}$ \\
\hline
\end{tabular}

Table (3) Show that the highest median level of homocystiene was detected in female patients with grade III( $21.6 \mathrm{M}$ mol/L) followed by grade II $(8.0 \mathrm{M} \mathrm{mol} / \mathrm{L})$ and grade I $(5.6 \mathrm{M} \mathrm{mol} / \mathrm{L})$ with no significant difference between different grades of AGA $(\mathrm{p}>0.05)$.

Table (3) Levels of homocystiene according to severity among female patients.

\begin{tabular}{|c|c|c|c|c|c|c|}
\hline \multirow[t]{2}{*}{ Female grades } & \multirow[t]{2}{*}{ n. } & \multicolumn{2}{|c|}{ Homocystiene (Mmol/L) } & \multirow[t]{2}{*}{ KW test } & \multirow[t]{2}{*}{$\mathbf{P}$} & \multirow{2}{*}{$\begin{array}{c}\text { Sig } \\
\text { pairs }\end{array}$} \\
\hline & & Median & Range & & & \\
\hline Grade I & 9 & 5.6 & $4.6-9.94$ & 5.43 & 0.066 & ----- \\
\hline Grade II & 30 & 8.0 & $5.1-25.1$ & & (NS) & \\
\hline Grade III & 21 & 21.6 & $6.8-34.8$ & & & \\
\hline
\end{tabular}

Homocystiene showed a significant $(\mathrm{p}<0.05)$ positive correlation with BMI $(\mathrm{r}=0.301$

Table (4) Correlation between level of homocysteine and the studied variables among the patients group

\begin{tabular}{lll}
\hline With & Homocysteine $(\mathbf{M ~ m o l} / \mathbf{L})$ & \\
\cline { 2 - 3 } & rho & $\mathbf{P}$ \\
\hline Age & 0.071 & 0.59 \\
BMI & 0.301 & $0.019(\mathrm{~S})$ \\
\hline
\end{tabular}

Over our consider homocystiene level might have been insignificantly higher Previously, patients who smoke versus non smokers. This might have been in understanding with [12], they exhibited that indifferent smokers are positively and freely connected with plasma homocysteine levels over a dose-dependent way. Our investigation also might have been On halfway assention for [13] ,they showed An critical higher $(\mathrm{p}<0.001)$ level about homocystiene "around smokers. This error is likely a direct result they incorporated patients for renal impedance same time the present consider excluded them. A few investigations for example, such that [14] , said that homocystiene expand On patients with renal disappointment Similarly as hyperhomocysteinemia 
happens Previously, chronic- and end-stage kidney sickness during those period At dialysis alternately transplant gets vital for survival. [15] Additionally stated that smoking auto might have been a critical autonomous determinants from claiming plasma homocysteine for multivariable straight relapse. This Contrast will be because of test span Similarly as they required an expansive example measure (2023 patients).

There might have been sure noteworthy connection between homocystiene level Also BMI and this might have been in understanding with[16], they showed An noteworthy larger amount for homocystiene $(\mathrm{P}=0$. 001) over stout patients Also distinguished An certain relationship the middle of BMI Furthermore homocysteine level. In the contary [17] showed no critical cooperation the middle of progressions to constitution impostor list Furthermore Hcy focuses About whether. However,they stated that homocystiene levels need aid identified with transforms in the individuals for incline constitution mass(LBM) alternately clinched alongside stout.

Although, The greater part of the female patients for extreme aga ( evaluation iii ) were large versus the individuals for gentle aga ( evaluation I) patients who required typical BMI, particular figure impostor list indicated no critical impact looking into different evaluations for aga. This might have been in understanding with[18], Similarly as they showed that overweight ladies for polycystic ovary syndrome needed essentially higher danger for female example hair misfortune over normal-weight ladies with polycystic ovary syndrome. This error might have been basically in light they incorporated female patients for polycystic ovary. As[19] , asserted that PCO may be generally connected with hyperandrogenism which is ahead of the principle reason for aga $\mathrm{On}$ females.

\section{Conclusion}

This prospective study showed that there were association between elevated homocystiene level ,smoking,BMI, and severity of androgenetic alopecia in addition to serum level of homocystiene can be used as an early prediction for AGA diagnosis.

\section{References}

[1] K.A.Gordon and A.Tosti , Alopecia: evaluation and treatment. Clin Cosmet Investig Dermatol , Vol.4,PP.101-106, 2011.

[2] E.Ludwig, Classification of the types of androgenetic alopecia (common baldness) occurring in the female sex.Br J Dermatol ,Vol.97,PP.247-54, 1977.

[3] P.Mansouri, M.Mortazavi, M.Eslami and M.Mazinani, Androgenetic alopecia and coronary artery disease in women. Dermatol Online J,Vol.11,PP.2, 2005.

[4] L.Borghans and BH.Golsteyn , Time Discounting and the Body Mass Index: Evidence from the Netherlands. Econ Hum Biol, Vol.4,PP.39-61,2006.

[5] JK.Wranicz, I.Cygankiewicz, M.Rosiak, P.Kula, K.Kula and W.Zareba, The relationship between sex hormones and lipid profile in men with coronary artery disease. Int J Cardiol, Vol.101,PP.105-10,2005

[6] S.Lata, D.Ajay, P. R. G, and A.Aruna, Androgenetic alopecia and risk of coronary artery disease. Indian Dermatol Online J, Vol.4(4),PP.283-287, 2013.

[7] S.Ahouansou, P.Le Toumelin, B.Crickx and V.Descamps, Association of androgenetic alopecia and hypertension. Eur J Dermatol,Vol. 17,PP. 220-2, 2007.

[8] A.Sadighha and G.M.Zahed, Evaluation of lipid levels in androgenetic alopecia in comparison with control group. J Eur Acad Dermatol Venereol,Vol. 23,PP.80-1,2009.

[9] S.B.Harmeet, K.M.Suresh, S.Sohan, and M.Mridula , Is Early Onset Androgenic Alopecia a Marker of Metabolic Syndrome and Carotid Artery Atherosclerosis in Young Indian Male Patients. Int J Trichology,Vol.7(4),PP.141-147, 2015.

[10] J.C.Ching-Yu, Y.Tzu-Ching, C. Christopher, L.ShaoChun, and C.Po-Yuan, Homocysteine is a bystander for ST-segment elevation myocardial infarction: a case-control study. BMC Cardiovasc Disord,Vol.18,PP.33, 2018.

[11] A.Baszczuk and Z.Kopczynski ,Hyperhomocysteinemia in patients with vitillgo. Vol.68, PP.579, 2014.

[12] D.B.Kim, Y.S.Oh, K.D.Yoo, J.M.Lee, C.S.Park, S.H.Ihm: Passive smoking in never-smokers is associated with increased plasma homocysteine levels. Int Heart J,Vol.51(3),PP.183-187, 2010.

[13] H.Feifei, C.Jie, L.Xun, H.Feng, C.Qingqing, P.Guicheng: Cigarette smoking reduced renal function deterioration in hypertensive patients may be mediated by elevated homocysteine .Oncotarget, Vol. 7(52),PP.86000-86010, 2016.

[14] E.A.Ostrakhovitch and S.Tabibzadeh: Homocysteine in Chronic Kidney Disease. Adv Clin Chem, Vol.72,PP.77-106, 2015.

[15] S.Jung, Y.Je, E.L.Giovannucci, B.Rosner, S.Ogino, E.Cho: Derivation and validation of homocysteine score in u.s. Men and women. Nutr,Vol.145(1), PP.96$104,2015$.

[16] K.J.Kumar, K.Saldanha, K.Sushma, D.S.Murthy, P.Vishwanath: A Prospective Study of Homocysteine and its relation to Body Mass Index and Lipid Profile in School Children .n Pediatr,Vol.54 (11),PP.935-937, 2017.

[17] S.B.Park, A.Georgiades, Changes in body composition predict homocysteine changes and hyperhomocysteinemia in Korea. J Korean Med Sci,Vol.28(7),PP.1015-10202, 2013.

[18] Y.A.Tu, S.J.Lin, P.L.Chen, C.H.Chou, C.C.Huang, H.N.H: HSD3B1 gene polymorphism and female pattern hair loss in women with polycystic ovary syndrome. J Formos Med Assoc, Vol.118(8), PP.1225-1231, 2019.

[19] I. Herskovitz, A.Tosti , Female pattern hair loss. Int J Endocrinol Metab,Vol. 21,11(4).e9860, 2013. 